\title{
Solvent-Free Mechanochemical Deprotection of $N$-Boc Group
}

\author{
Mateja Đud, Davor Margetić ${ }^{*}$ \\ Division of Organic Chemistry and Biochemistry, Ruđer Bošković Institute, Zagreb, Croatia \\ Email: *margetid@irb.hr
}

How to cite this paper: Đud, M. and Margetić, D. (2017) Solvent-Free Mechanochemical Deprotection of $\mathrm{N}$-Boc Group. International Journal of Organic Chemistry, 7, 140-144.

https://doi.org/10.4236/ijoc.2017.72011

Received: April 2, 2017

Accepted: June 5, 2017

Published: June 8, 2017

Copyright (c) 2017 by authors and Scientific Research Publishing Inc. This work is licensed under the Creative Commons Attribution International License (CC BY 4.0).

http://creativecommons.org/licenses/by/4.0/

\begin{abstract}
Boc protection group could be readily removed in a very mild mechanochemical conditions. In a short reaction time, ball milling of Boc-protected amines with $p$-toluenesulfonic acid in solvent-free conditions affords corresponding amine $p$ - $\mathrm{TsOH}$ salts.
\end{abstract}

\section{Keywords}

Green Chemistry, Mechanosynthesis, Boc Deprotection

\section{Introduction}

To address the issue of development of synthetic procedures which are environmentally more friendly, chemists have established different approaches and techniques [1]. Novel synthetic methods are focused on the economy of process by the reduction of waste production, either by application of more efficient catalysts, or procedures. The reduction of energy consumption during the synthesis also decreases impact on the environment, for instance more efficient heat transfer was achieved by employment of microwaves. Photochemistry employs light as a renewable energy source as a method for energy input. One of the methods for minimization of impact on the environment is the replacement of toxic reactants with less toxic. The replacement of solvents by less harmful, and ultimately water as the most benign, and conduction of reactions in solvent-free conditions would be the ultimate goal. Organic reactions could be effectively carried out without the presence of solvent in a microwave reactor, or simply by grinding reactants using mortar and pestle. Manual grinding is often associated with low reproducibility of results, and automated grinding in ball milling machines is gradually gaining in importance. Recent literature demonstrates the utility of mechanosynthesis in many common organic reactions [2]. This method is often 
adventitious over classical synthesis in solution in terms of reaction yield, reaction time, simplicity of workup, use of energy and solvents. In our ongoing research program on development of eco-friendly synthetic protocols [3], we investigated the applicability of mechanosynthesis in deprotection of Boc-protected amines, as a widely used protection group. As far as we are aware, ball milling technique was only used in amine Boc protection with di-tert-butyl dicarbonate [4] and synthetic methods for solvent-free removal of Boc group were reported in several papers. These include grinding in a mortar with iodine [5], thermolysis at $180^{\circ} \mathrm{C}-185^{\circ} \mathrm{C}$ [6], or by thermolysis on silica gel at mild temperature $\left(50^{\circ} \mathrm{C}\right)$ at reduced pressure [7] [8]. Microwave-assisted thermolytic deprotection was achieved on silicagel within $1 \mathrm{~min}$ [9] or by MW heating on neutral alumina with $\mathrm{AlCl}_{3}$ in $1 \mathrm{~min}$ [10]. For deprotecion at low temperatures (rt to $40^{\circ} \mathrm{C}$ ), Lewis acid, $\mathrm{YbTf}_{3}$ was added on silicagel [11]. The objective of this account was to study the viability of solvent-free mechanochemical $N$-Boc deprotection reaction. Novel mechanochemical methodology could find its application in different areas of organic chemistry and complement existing synthetic methods.

\section{Results and Discussion}

When substrate 1 was ball milled with catalytic amount of iodine, or with silicagel for 60 minutes at room temperature, deprotection was not observed, which is in variance to our assumptions based on the published results. In principle, transfer from manual to automated grinding should facilitate reaction, and mild heat generated in ball milling vessel should be cooperative in deprotection by neat grinding. We have found that the mechanochemical removal of $N$-Boc group was effected by the solvent-free ball milling of substrate 1 with an excess of $p$-toluenesulfonic acid (Scheme 1), which is a modification of the procedure employing MW heating of substrates with $p$-TsOH [12].

Mechanochemical removal of Boc group by $p-\mathrm{TsOH}$ was applied to substrates 1-5 and the corresponding tosylate salts were obtained in almost quantitative yields in short reaction time of $10 \mathrm{~min}$ at room temperature (Table 1). Reaction progress followed by TLC and NMR spectra of crude reaction mixtures indicate full conversion to products. Simple workup procedure consists of precipitation of products from suspension in dichloromethane. Inspection of results presented in Table 1 reveals that these mild reaction conditions are suitable for chemoselective deprotection of Boc-protected primary amines and do not affect cleavage of other amide or ester groups. In addition to simple alkyl amines, we have shown that this method is applicable to amino acids and their derivatives.

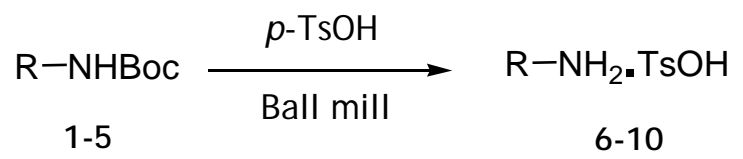

Scheme 1. Deprotection of $N$-Boc group by ball milling. 
Table 1. Deprotection of $N$-Boc group in ball milla

Entry

${ }^{\mathrm{a}} 10 \mathrm{~min}$; isolated yields, calculated on the basis of the moles of substrate.

\section{Conclusion}

A novel, simple solvent-free synthetic procedure for $N$-Boc removal in ball mill in very mild reaction conditions at room temperature is described. This method has potential application in Boc group deprotection of other types of amines, in various fields such as synthesis of pharmaceutically interesting molecules, natural product synthesis, or organic material science.

\section{Experimental}

General. Retsch MM400 mixer mill was used for ball milling experiments at frequency of $30 \mathrm{~Hz}$, with stainless steel vessel $(10 \mathrm{~mL})$ and one stainless steel ball $(10 \mathrm{~mm})$. Solution ${ }^{1} \mathrm{H}$ NMR spectra were acquired on Brucker Avance (300 and $600 \mathrm{MHz}$ ) spectrometers in deuterated DMSO with tetramethylsilane as an internal standard. FTIR-ATR spectra were recorded using a Fourier Transform-Infrared Attenuated Total Reflection PerkinElmer UATR Two spectrometer in the range $400 \mathrm{~cm}^{-1}$ to $4000 \mathrm{~cm}^{-1}$.

General procedure for Boc deprotection. A mixture of Boc-protected amine and 2 equivalents of $p$-toluenesulfonic acid monohydrate per Boc group was ground neat using $10 \mathrm{~mm}$ stainless steel ball at $30 \mathrm{~Hz}$ for 10 minutes at room temperature. The crude mixture was suspended in dichloromethane and the precipitate was collected by filtration. The resulting solid was air-dried to give deprotected amine as toluenesulfonic salt. In the case of 1 , the crude mixture was soluble in dichloromethane, so the solution was evaporated to give the final product. Purity of all $p$-toluenesulfonate salts is evidenced by NMR spectroscopy, IR spectrometry and thin layer chromatography.

$N$-aminopropyl- $N$-(L-phenylalanine methyl ester)oxalamide $p$-toluenesulfonate (6)

White solid (quant. yield) ${ }^{1} \mathrm{H}-\mathrm{NMR}$ (DMSO- $\left.d_{6}\right): \delta(\mathrm{ppm}) 1.65-1.77(\mathrm{~m}, 2 \mathrm{H}$, $\left.\mathrm{CH}_{2}\right), 2.29$ (s, 6H, $\mathrm{CH}_{3}$-tol), $2.69-2.79\left(\mathrm{~m}, 4 \mathrm{H}, \mathrm{CH}_{2}\right), 3.11-3.21\left(\mathrm{~m}, 4 \mathrm{H}, \mathrm{CH}_{2}\right)$, 3.65 (s, 3H, $\left.\mathrm{CH}_{3}\right), 4.54-4.64(\mathrm{~m}, 1 \mathrm{H}, \mathrm{CH}), 7.14$ (d, 4H, J = 7.9 Hz, Ar-tol), 7.19 $7.31(\mathrm{~m}, 5 \mathrm{H}, \mathrm{ArH}), 7.49$ (d, $4 \mathrm{H}, \mathrm{J}=7.9 \mathrm{~Hz}, \mathrm{Ar}-\mathrm{tol}), 7.67$ (brs $\left.3 \mathrm{H}, \mathrm{NH}_{3}^{+}\right), 8.87$ (t, 
$1 \mathrm{H}, \mathrm{J}=6.3 \mathrm{~Hz}, \mathrm{NH}), 8.96(\mathrm{~d}, 1 \mathrm{H}, \mathrm{J}=8.7 \mathrm{~Hz}, \mathrm{NH}) . \mathrm{IR}(\mathrm{ATR}) v_{\max } / \mathrm{cm}^{-1} 3354$, $3307,3059,2965,1741,1681,1658,1507,1446,1244,1169,1122,1033,1005$, $855,815,745,701,683,562,529$.

\section{1,3-diamino $p$-toluenesulfonate (7)}

White solid (quant. yield) ${ }^{1} \mathrm{H}-\mathrm{NMR}\left(\mathrm{DMSO}-d_{6}\right): \delta(\mathrm{ppm}) 1.78-1.91(\mathrm{~s}, 2 \mathrm{H}$, $\mathrm{CH}_{2}$ ), 2.29 (s, 6H, CH Ar-tol), 7.51 (d, $4 \mathrm{H}, \mathrm{J}=7.9 \mathrm{~Hz}$, Ar-tol), 7.79 (brs $6 \mathrm{H}, \mathrm{NH}_{3}^{+}$). IR (ATR) $v_{\max } / \mathrm{cm}^{-1}$ 3061, 2970, 1710, 1598, 1526, 1494, 1390, 1188, 1118, 1028, 999, 814, 678, 558.

\section{1,5-diaminopentane $p$-toluenesulfonate (8)}

White solid (quant. yield) ${ }^{1} \mathrm{H}-\mathrm{NMR}$ (DMSO- $\left.d_{6}\right): \delta(\mathrm{ppm}) 1.26-1.38(\mathrm{~m}, 2 \mathrm{H}$, $\mathrm{CH}_{2}$ ), $1.46-1.59$ (s, 4H, $\mathrm{CH}_{2}$ ), 2.29 (s, 6H, $\mathrm{CH}_{3}$-tol), 2.76 (t, 4H, J = 7.7 Hz, $\mathrm{NCH}_{2}$ ), 7.13 (d, 4H, J = 8.1 Hz, Ar-tol), 7.49 (d, 4H, J = 8.1 Hz, Ar-tol), 7.64 (brs $6 \mathrm{H}, \mathrm{NH}_{3}^{+}$). IR (ATR) $v_{\max } / \mathrm{cm}^{-1} 3487,3059,1600,1536,1495,1160,1120,1032$, $1008,816,682,564$.

\section{D-alanine $p$-toluenesulfonate (9)}

White solid (quant. yield) ${ }^{1} \mathrm{H}-\mathrm{NMR}$ (DMSO- $\left.d_{6}\right): \delta(\mathrm{ppm}) 1.36(\mathrm{~d}, 3 \mathrm{H}, \mathrm{J}=7.5$ $\mathrm{Hz}, \mathrm{CH}_{3}$ ), 2.27 (s, 3H, $\mathrm{CH}_{3}$-tol), $2.47-2.49$ (m, 1H, CH), 7.10 (d, 2H, J = 8.7 Hz, Ar-tol), 7.46 (d, $2 \mathrm{H}, \mathrm{J}=8.7 \mathrm{~Hz}$, Ar-tol), 8.14 (brs $3 \mathrm{H}, \mathrm{NH}_{3}^{+}$). IR (ATR) $v_{\max } / \mathrm{cm}^{-1}$ $3065,2946,1747,1599,1518,1495,1462,1199,1157,1122,1108,1036,1008$, $922,852,813,682,556$.

\section{Glycine $p$-toluenesulfonate (10)}

White solid (quant. yield) ${ }^{1} \mathrm{H}-\mathrm{NMR}$ (DMSO- $\left.d_{6}\right): \delta(\mathrm{ppm}) 2.29$ (s, 3H, $\mathrm{CH}_{3}$-tol), 3.69 (q, 2H, J = 5.4 Hz, $\mathrm{CH}_{2}$ ), 7.12 (d, 2H, J = 7.9 Hz, Ar-tol), 7.48 (d, $2 \mathrm{H}, \mathrm{J}=7.9 \mathrm{~Hz}$, Ar-tol), 8.07 (brs $3 \mathrm{H}, \mathrm{NH}_{3}^{+}$). IR (ATR) $v_{\max } / \mathrm{cm}^{-1} 3051,2952$, 2549, 1747, 1591, 1494, 1438, 1226, 1153, 1117, 1033, 1009, 925, 858, 817, 680, $581,552,497$.

\section{Acknowledgements}

The financial support of this work by the Croatian Science Foundation (grant No. 9310) is acknowledged.

\section{References}

[1] Tundo, P., Perosa, A. and Zecchini, F., Eds. (2007) Methods and Reagents for Green Chemistry: An Introduction. John Wiley \& Sons, Hoboken.

[2] Margetić, D. and Štrukil, V. (2016) Mechanochemical Organic Synthesis. Elsevier, Amsterdam.

Margetić, D. (2005) Mechanochemical Organic Reactions without the Use of Solvents. Kemija u Industriji, 54, 351-358.

http://pierre.fkit.hr/hdki/kui/vol54/broj07-08/351.pdf

[3] Đud, M., Magdysyuk, O.V., Margetić, D. and Štrukil, V. (2016) Synthesis of Monosubstituted Thioureas by Vapour Digestion and Mechanochemical Amination of Thiocarbamoyl Benzotriazoles. Green Chemistry, 18, 2666-2674. http://pubs.rsc.org/en/Content/ArticleLanding/2016/GC/C6GC00089D\#!divAbstract https://doi.org/10.1039/C6GC00089D

Glasovac, Z., Trošelj, P., Jušinski, I., Margetić, D. and Eckert-Maksić, M. (2013) Synthesis of Highly Basic Hexasubstituted Biguanides by Environmentally Friendly 
Methods. Synlett, 24, 2540-2544.

https://www.thieme-connect.com/ejournals/abstract/10.1055/s-0033-1339876 Štrukil, V., Margetić, D., Igrc, M. D., Eckert-Maksić, M. and Friščić, T. (2012) Desymmetrisation of Aromatic Diamines and Synthesis of Non-Symmetrical Thiourea Derivatives by Click-Mechanochemistry. Chemical Communications, 48, 9705-9707. http://pubs.rsc.org/en/content/articlelanding/2012/CC/C2CC34013E

Štrukil, V., Bartolec, B., Portada, T., Đilović, I., Halasz, I. and Margetić, D. (2012) One-Pot Mechanosynthesis of Aromatic Amides and Dipeptides from Carboxylic Acids and Amines. Chemical Communications, 48, 12100-12102.

http://pubs.rsc.org/en/content/articlehtml/2012/cc/c2cc36613d

[4] Sikchi, S.A. and Hultin, P.G. (2006) Solventless Protocol for Efficient Bis- $N$-Boc Protection of Adenosine, Cytidine, and Guanosine Derivatives. The Journal of Organic Chemistry, 71, 5888-5891. http://pubs.acs.org/doi/abs/10.1021/jo060430t Konnert, L., Gauliard, A., Lamaty. F., Martinez, J. and Colacino, E. (2013) Solventless Synthesis of $N$-Protected Amino Acids in a Ball Mill. ACS Sustainable Chemistry \& Engineering, 1, 1186-1191. http://pubs.acs.org/doi/abs/10.1021/sc4001115

[5] Kumar, G.P., Rambabu, D., Rao, M.V.B. and Pal, M. (2013) Iodine-Mediated Neutral and Selective $N$-Boc Deprotection. J. Chem, Article ID: 916960.

[6] Rawal, V.H. and Cava, M.P. (1985) Thermolytic Removal of t-butyloxycarbonyl (BOC) Protecting Group on Indoles and Pyrroles. Tetrahedron Letters, 26, 61416142. https://doi.org/10.1016/S0040-4039(00)95036-6

[7] Wensbo, D., Annby, U. and Gronowitz, S. (1995) Indole-3-Acetic Acids and Hetero Analogues by One Pot Synthesis including Heck Cyclisation. Tetrahedron, 51, 10323 10342. https://doi.org/10.1016/0040-4020(95)00601-4

[8] Apleqvist, T. and Wensbo, D. (1996) Selective Removal of the $N$-BOC Protective Group Using Silica Gel at Low Pressure. Tetrahedron Letters, 37, 1471-1472. https://doi.org/10.1016/0040-4039(95)02398-4

[9] Siro, J.G., Martín, J., García-Navío, J.L., Remuiñan, M.J. and Vaquero, J.J. (1998) Easy Microwave Assisted Deprotection of N-Boc Derivatives. Synlett, 147-148. https://www.thieme-connect.com/products/ejournals/abstract/10.1055/s-1998-1604 https://doi.org/10.1055/s-1998-1604

[10] Bose, D.S. and Lakshminarayana, V. (1998) An Efficient and Highly Selective CleavAge of N-Tert-Butoxycarbonylgroup under Microwave Irradiation. Tetrahedron Letters, 39, 5631-5634. https://doi.org/10.1016/S0040-4039(98)01094-6

[11] Kotsuki, H., Ohishi, T., Araki, T. and Arimura, K. (1998) A Facile New Method for Selective Deprotection of N-(tert-butoxycarbonyl)-Protected Carboxamides with $\mathrm{Yb}(\mathrm{OTf})_{3}$ Supported on Silica Gel. Tetrahedron Letters, 39, 4869-4870. https://doi.org/10.1016/S0040-4039(98)00950-2

[12] Suresh Babu, V.V., Patil, B.S. and Vasanthakumar, G.-R. (2005) MW-Enhanced High-Speed Deprotection of Boc Group Using $p$-TsOH and Concommitant Formation of N-Me-Amino Acid Benzyl Ester p-TsOH Salts. Synthetic Communications, 35, 1795-1802. https://doi.org/10.1081/SCC-200063953 
Submit or recommend next manuscript to SCIRP and we will provide best service for you:

Accepting pre-submission inquiries through Email, Facebook, LinkedIn, Twitter, etc. A wide selection of journals (inclusive of 9 subjects, more than 200 journals)

Providing 24-hour high-quality service

User-friendly online submission system

Fair and swift peer-review system

Efficient typesetting and proofreading procedure

Display of the result of downloads and visits, as well as the number of cited articles Maximum dissemination of your research work

Submit your manuscript at: http://papersubmission.scirp.org/

Or contact ijoc@scirp.org 